\title{
Factors Affecting Herbicide Use in Fruits and Vegetables ${ }^{1}$
}

\author{
C. E. Rouse and P. J. Dittmar ${ }^{2}$
}

\section{Introduction}

Proper herbicide application is critical for fruit and vegetable growers to effectively manage weeds. Improper herbicide application may lead to herbicide loss from the targeted area, increased crop injury, and reduced weed control.

Growers need to take into account a number of factors before and during application in any crop to ensure the herbicide is effective. Herbicide efficacy (or effectiveness) is greatly affected by timing and environmental conditions. Although complete weed control is not always possible, even slight reductions in weed populations can greatly enhance productivity in fruit and vegetable crops. Always consult the label for any questions regarding proper placement, stage of crop growth, or mixing restrictions prior to any chemical application. The label is a legal document and gives the standards set by the pesticide manufacturer and state regulations.

This publication reviews techniques and processes to help growers properly apply herbicides. Understanding the processes and applying the following techniques will help to increase the overall efficacy of herbicides in fruit and vegetable production.

\section{Herbicide Application Methods}

An important step in applying herbicides is to determine the correct timing of application during the production year. Herbicides that control seedling growth (pre-plant incorporated or preemergence) or actively growing plant tissue (postemergence) must be applied at the right time. Timing is important to maximize weed control and limit crop injury.

\section{Pre-Plant Incorporated}

Pre-plant incorporated (PPI) herbicides are applied before the crop is in the ground and are incorporated into the soil to control emerging weeds. These herbicides are typically used to suppress weed growth and help the crop to establish, increasing its competitive ability against weeds. Incorporation is typically completed using an irrigation event or mechanical tillage. This enhances the weed control activity of the herbicide by properly distributing it within the soil. Because of shallow root systems in fruit crops, PPI herbicides are not typically incorporated through cultivation in these crops.

\section{Preemergence}

A preemergence (PRE) herbicide is applied over the top of a bed or field after seeding a crop and prior to emergence of the crop and/or weed. These types of herbicides are very similar to PPI and work to suppress weeds early during the growing season. PRE herbicides typically require some form of incorporation to increase efficacy. Different crops require this application at different times. Plants grown

1. This document is HS1219, one of a series of the Horticultural Sciences Department, Florida Cooperative Extension Service, Institute of Food and Agricultural Sciences, University of Florida. Original publication date May 2013. Please visit the EDIS website at http://edis.ifas.ufl.edu.

2. C. E. Rouse, graduate assistant, and P. J. Dittmar, assistant professor, Horticultural Sciences Department; Florida Cooperative Extension Service, Institute of Food and Agricultural Sciences, University of Florida, Gainesville, FL 32611. 
from seed, such as sweet corn, receive application after sowing of seeds. In crops such as potato, PRE herbicides are applied before reemergence after the dragging-off process. In fruit crops, PRE herbicides are applied in early spring and late summer for control of warm- and cool-season annuals.

\section{Postemergence - Overtop}

Herbicides with this application method are applied over top of both the crop and weeds. These herbicides reduce the in-row competition caused by weeds and are more selective than herbicides for row middles only. This type of herbicide will not cause significant injury to the crop when properly applied, but labeled weeds will be controlled with an application. Always consult the label for mixing and instructions related to the crop to ensure crop damage does not occur.

\section{Postemergence - Directed}

Herbicides with this application method are used during the crop production cycle, but they are sprayed so that the herbicide is directed onto the weed and away from the crop's leaves or foliage, where the risk of absorption and injury is higher. In fruits and vegetables, these sprays are made toward the plant base and do contact the older, more mature portion of the crop, effectively reducing herbicide damage.

\section{Postemergence - Shielded}

In this application method, a shield or hood is used to prevent the herbicide from coming in contact with the crop. This minimizes drift and directs the spray to the weed and not the crop. This requires special equipment and is typically only used at certain times of the crop growth cycle.

\section{Tank-Mixing}

Tank-mixing herbicides is an effective way to reduce the number of applications made during a season and take advantage of different application methods. Tank-mixing is adding two or more herbicides to the same tank and applying them in one application timing. In some instances, multiple PRE or POST (postemergence) herbicides are combined in a tank-mix to increase the control of a wider weed spectrum, such as broadleaves and grasses. A tank-mix of a PRE and POST herbicide is sometimes used in fruit and vegetable crops to increase overall herbicide efficacy. The POST herbicide will control the weeds that are present, and the PRE herbicide will extend control throughout the season. Consult the herbicide labels for information because some chemicals may or may not be tank-mixed.

\section{Growth Timing}

When applying an herbicide, the applicator must take into account the growth stage of both the crop and the weeds present in the field. Some herbicides have better control at certain weed stages but result in increased injury if applied at the wrong time in the cropping cycle.

\section{Crop Growth Stage}

Crop growth stage is an important consideration for application. This will help to reduce the associated crop damage from applying the herbicide. Note the plant size when applying the herbicide. The age or growth stage restrictions take into account characteristics of a typical plant at that point of its growth. If the applicator feels the plant is not at that stage, he or she should use caution when applying the herbicide to reduce damage or loss. Herbicide labels for vegetable crops will usually state a certain number of true leaves, plant height, or stage of flowering. Fruit crops typically have restrictions based on the number of years the crop has been growing in the ground or the crop bearing fruit within a year of application. Consult the herbicide label prior to application. The label is the law and must be followed.

\section{Weed Growth Stage}

Weed growth stage is also important to increase the efficacy of the herbicide at application. Applying herbicides when the weeds are as young and small as possible will best control weeds. Young plants have not developed natural barriers to chemical entry and will absorb the herbicides more readily than more mature plants. Larger leaves typically absorb more of a chemical than smaller leaves because of the greater surface area present. Application to these larger and typically older leaves will help even though other barriers may be present. An older, more weathered plant will have greater protection against chemicals, and efficacy is significantly reduced. Older plants have a much thicker cuticle, or waxy coating, on the leaf surface that helps protect it from the environment. Larger, older weeds better deter chemical entry and prevent the herbicide from being as effective as it is on younger plants.

\section{Environmental Conditions}

Increasing herbicide efficacy requires understanding the environmental conditions at the time of application. Herbicides should be applied when the environment is most optimal for uptake and control of weeds. The following conditions can prevent or decrease herbicide efficacy. 


\section{Wind}

High wind speed contributes to herbicide movement and loss from the targeted area during application. Drift occurs when the wind moves the herbicide from the targeted area to an undesired location. When applying herbicides, consider wind direction and speed to prevent drift and possible injury to non-targeted plants.

\section{Temperature}

Drought stress, a condition in plants caused by lack of water, can be a major hindrance to herbicide efficacy. In this condition, weeds will not uptake or move water and other substances around the plant. Some of the herbicides require this translocation to work properly. In some instances, a lack of water in the soil will prevent herbicides from being activated. The more drought stressed a plant is, the thicker its cuticle will be. Cuticles form to help prevent water loss and will also prevent chemical movement.

Low temperature during or directly following application increases the likelihood of herbicide injury. Lower temperatures generally slow crop growth, which results in prolonged herbicide exposure. Under normal conditions there is little to no injury, but longer exposure can cause negative effects on growth.

Relative humidity also plays an important role in both herbicide uptake and reduced efficacy. Low relative humidity will result in greater moisture evaporation. Because water is the carrier for most herbicides, evaporation will leave the active ingredient on the weed and slow its movement into the plant. At high relative humidity, spray droplets will remain on the crop surface for longer periods of time, resulting in possible crop injury. A combination of warm temperatures and good relative humidity will increase the weeds' herbicide uptake and increase weed control.

\section{Moisture}

Presence of dew at the time of application causes spray dilution and reduces the overall herbicide efficacy. The amount of water in the spray tank is predetermined for a specific herbicide concentration intended to achieve ideal weed control; dew on the foliage will lower the herbicide concentration. Any substantial increase in water will reduce how effective the active ingredient will be on the weed species. Higher concentrations of dew on a leaf surface will cause the herbicide to run off and be lost from the leaf surface. This will reduce weed control and put the herbicide in an unintended area.

\section{Soils Conditions}

Weather conditions are not the only environmental component that should be considered for herbicide efficacy. Soil conditions also contribute to how effectively herbicides control weeds.

\section{Soil pH}

Soil $\mathrm{pH}$ affects the overall activity of a given herbicide. Herbicides are effective at certain $\mathrm{pH}$ ranges because of their chemical makeup. If the soil conditions are outside of that favorable range, the chemical will become inactive or limited in its control, decreasing its overall efficacy.

\section{Organic Matter}

Organic matter is present in many forms in soil and interacts greatly with some herbicides, especially preemergence herbicides, to reduce the control of weeds. Herbicides are usually organic compounds and have a great ability to bind to other organic compounds. High amounts of organic matter will reduce the amount of chemical present for control and reduce its effectiveness. This is very similar to oil and water combinations on your dishes; oil and water don't mix well, but when you add soap, an organic compound, you can remove the oil from the surface. Organic matter will allow the chemical to persist in the soil profile for a long period of time. Over time and as the environment changes, the chemical may be released and cause crop injury. The organic matter may alter the soil $\mathrm{pH}$ and have the same effects that were previously mentioned.

\section{Cation Exchanage Capacity (CEC)}

Cation exchange capacity (CEC) is a property that gives soil the ability to bind and release different nutrients or compounds on the soil particle. Higher CEC means there is a greater ability for exchange on the soil particles. This can be dictated by the soil's $\mathrm{pH}$ and organic matter content. Low CEC indicates a reduction in the soil's ability to hold onto compounds. Usually these soils have a greater risk of herbicide movement, so it is important to take measures that will reduce herbicide movement in low CEC soils. The deep sandy soils of Florida tend to have low CEC. Different soils will have different CEC; a soil test will help you determine your soil's CEC.

\section{Herbicide Loss and Inactivation}

Herbicide effectiveness requires that the applied chemical is available when it is needed for weed control. Improper application can result in herbicide loss from the targeted area and cause a reduced effect on control. Herbicides are 
"lost" or inactivated in a number of different ways in an agricultural system.

\section{Immobilization}

Different soil properties result in organic chemicals such as herbicides having different behaviors in the soil. As previously mentioned, organic matter, $\mathrm{pH}$, and CEC may prevent proper control. High organic matter, high CEC, and high clay and silt content in soils will result in the chemicals adsorbing to particles in the soil. Always perform a soil test in your field to understand the soil's properties. Management decisions should be made based on the test results. Certain chemicals or additives should be used to prevent any reduced activity under unfavorable conditions.

\section{Volatilization}

Herbicides that remain on the surface of soil and plants for long periods of time run the risk of being volatilized, or lost as a vapor. Under hot temperatures and decreased relative humidity, some herbicides become lost to the atmosphere. Volatilization can be reduced if applications are timed properly and herbicides are incorporated as needed. A good way to prevent volatilization is to apply herbicides early in the morning when temperatures are cooler and before the sun reaches its peak. If the herbicide is applied at the soil surface, thorough incorporation with irrigation or tillage may be needed. This helps to position the herbicide lower in the soil profile and prevent exposure at the surface.

\section{Water Flow}

Rainfastness is a chemical's ability to withstand rain events after application. Herbicide labels will provide information regarding the time it takes for the chemical to become rainfast. Water flow can be a major contributing factor for herbicide movement in the environment. Natural rain events are uncontrollable. An applicator must monitor the weather to prevent loss before the herbicide becomes rainfast.

Erosion may occur as a result of excessive amounts of heavy rainfall moving soil that contains chemicals away from the targeted area. Application should be avoided if this is a possibility in the near future following application. Tillage practices in a field resulting in loose or poorly structured soil will also cause erosion. Proper tillage techniques should be used to prevent soil erosion and herbicide loss. It may be beneficial to develop a natural border around the field to prevent herbicide loss from erosion. Planting grasses between the field and irrigation ditches will prevent the soil from moving too far out and prevent possible herbicide runoff into neighboring water bodies.

Leaching is also a result of high amounts of rain or irrigation moving the chemical from the top soil layer deeper into the profile. It is possible to get leaching from over-irrigation during incorporation; monitor your system to avoid this. Herbicide leaching runs the risk of environmental damage and reduction in control.

\section{Degradation}

Herbicide degradation is when the chemical is broken down from its original formula into an inactive and unusable form. The environment is a major factor involved in the breakdown or transformation of chemicals, and proper timing will help slow these processes. Soils are affected by a number of factors that may encourage herbicide breakdown. Microorganisms found in soils provide a number of benefits but can also affect herbicide longevity in the soil. Healthy, well-drained, and properly managed soils will help reduce herbicide degradation.

Photodegradation is UV light breaking down the chemical at the soil surface. Once again, proper incorporation after application will reduce the occurrence of photodegradation. Herbicide labels will provide information on the chemical's photodegrading characteristics.

Microbial degradation is when small microbes naturally present in the soil consume the carbon-rich chemicals. This form of degradation is usually the most common form of breakdown. It is hard to prevent, but avoiding soil application in microbe-rich soils may help to reduce loss.

\section{Adjuvants}

A chemical adjuvant is any substance added to a mixture to increase its overall efficacy. Different adjuvants provide different forms of assistance. Surfactants and crop oils are the adjuvants primarily used in herbicide applications. These two are used to increase the surface activity of an herbicide. Surfactants help spread the spray droplets on the plant, increasing the area the spray material covers on the weed. Crop oil works to break down the outer cuticle layer on the plant and increase chemical penetration. An adjuvant should be selected based only on the label for the herbicide you are using. Some adjuvants may prevent activity or cause damage if not applied properly. For further information on adjuvants and adjuvant selection, visit http://edis.ifas.ufl. edu/wg050. 